\title{
Characteristics and Neurological Manifestations of Patients with Operated Lumbar Disc Herniation
}

Amir Mohammad Bazzazi ${ }^{1}$, Amir Abbas Ghasemi ${ }^{1 *}$, Roghayeh Mirsoltani $^{1}$

1.Department of Neurosurgery, Urmia University of Medical sciences, Urmia, Iran

\begin{abstract}
Background and aim: Lumbar disk herniation is one of the most common causes of surgery in the spine with a variety of signs and symptoms. Sensory and motor deficits, as well as reflex and autonomic abnormalities may be seen. This study aimed to investigate characteristics and neurological manifestations in a series of operated cases with lumbar disc herniation. Methods: In a retrospective setting, profiles of 163 operated cases with lumbar disc herniation were reviewed. Demographics as well as preoperational sign and symptoms were extracted and evaluated. Results: There were 86 females and 77 males with a mean age of $44.85 \pm 0.91$ (range: 23-78) years in the studied population. The most common involved levels were L4-L5 and L5-S1, respectively. Low back pain, radicular pain, and positive Lasegue test were documented in 98.2\%, 96.9\% and $77.3 \%$ of the patients, respectively. Sensory, motor and reflexive abnormalities were documented in $66.3 \%, 51.5 \%$ and $19.6 \%$ of the cases, respectively. Sphincter and sexual dysfunction was presented in $4.9 \%$ and $1.2 \%$, respectively. Conclusion: Clinical and neurological signs of operated patients with lumbar disc herniation in the studied center are not far different from available reports in this regard.
\end{abstract}

Keywords: Lumbar disk herniation; Signs and symptoms; Surgery

\section{Introduction}

Disc herniation is one of the most frequent problems all over the world, with an incidence of 1 in 32 in the United States (1). Lumbar disc herniation is one the most frequent subtypes of intervertebral disc herniations in the spine, with the highest incidence in individuals over 30 years (2). Many factors constitute etiologies of disc herniation; such as demanding jobs/sports, chronic stress, trauma, aging, smoking, nutritional deficiencies, genetic predisposition and anatomical abnormalities $(3,4)$. Low back pain is the most common symptom of patients with disc herniation. Radicular pain, sensory and motor deficits, reflex abnormalities, sphincter dysfunction, urinary and/or fecal

\section{Corresponding author:}

Amir Abbas Ghasemi

Department of Neurosurgery, Urmia University of Medical sciences, Urmia, Iran

E-mail: dr.amirghasemi@ymail.com

Received: 14-05-2013 Accepted: 28-05-2013 Published: 07-06-2013

doi:10.7575/aiac.abcmed.v.2n.1p.26 
incontinence, and sexual dysfunction may also be seen $(2,5)$. However, available reports are heterogeneous regarding the frequency of signs and symptoms of lumbar disc herniation. Mirhoseini (6) studied 745 patients with operated lumbar disc herniation. Radicular pain, sensory/reflex abnormalities and motor deficit were documented in $99 \%, 75 \%$, and $27 \%$ of the cases respectively. In another series on 101 operated patients, low back pain, radicular pain, motor abnormalities and reflex problems were present in $90 \%, 82.4 \%$ and $43.6 \%$, respectively (7). Porchet et al. (8) reported motor deficit in $78.8 \%$ and sensory deficit in $46.6 \%$ of the 178 studied operated cases. In another study in Germany, 165 adolescents and young adults with operated lumbar disc herniation were investigated. Segmental sensory deficit was present in $66.8 \%$, reflex abnormalities in $61.8 \%$, and motor deficits in $50.3 \%$ (9). In an Indian series by Janardhana et al. (10) on 119 cases, neurological deficits were present in 36 patients, including 20 combined sensory-motor and 13 pure sensory complications. In another study by Jain and Kumar (11) in India on 123 patients, neurologic deficit was present in 73 patients. Due to wide range of reports in this regard, this study aimed to report characteristics and clinical findings of a series of patients with operated lumbar disk herniation.

\section{Methods and Materials}

In this retrospective study, profiles of 163 operated patients with lumbar disc herniation were reviewed in Urmia Imam Khomeini Center, Urmia, Iran, from 2011 to 2012. Only profiles with verified complete data were enrolled. Sample size was calculated based on the findings of Mehrazin et al. study (7) which used radicular pain as the main outcome $(d=0.05$, $p=0.9$ and $\alpha=0.05)$. Accordingly, 138 patients were required for this study which was increased to 163 cases based on available cases within the target period of time. The studied variables included age, sex, signs and symptoms, level of involvement and operation, type of operation, and duration of hospital stay. All the variables were compared between two sexes and different age groups. This study was approved by the ethics committee of Urmia Medical University. SPSS Software for Windows (ver.18.0, SPSS Inc., IL, USA) was used for analysis. The Independent samples $t$ test, the Chi-square $\left(\chi^{2}\right)$ test, and the Fishers' Exact test were used, when appropriate, for comparisons. A $p$-value $\leq 0.05$ was considered statistically significant.

\section{Results}

One hundred and sixty-three operated cases with lumbar disc herniation, including 86 females (52.8\%) and 77 males (47.2\%) with a mean age of $44.85 \pm 0.91$ (range: $23-78$ ) years were studied. Chief complains of the studied population were low back pain in 158 cases $(96.9 \%)$, pain in lower extremities in 3 cases $(1.8 \%)$, radicular pain in 2 cases $(1.2 \%)$. While low back pain was present in 160 patients (98.2\%), radicular pain was also present in 158 cases $(96.9 \%)$, including right leg in 68 cases $(41.7 \%)$, left leg in 68 cases $(41.7 \%)$, and both legs in 22 cases (13.5\%). The mean duration of symptoms was $22.80 \pm 2.99$ (range: 1-180) months in 135 patients, and several years in the remaining. Findings of examination at the time of admission were sensory deficits in 108 cases (66.3\%), motor deficit in 84 cases (51.5\%), and positive Lasegue test in 126 cases (77.3\%) (right side in 56 cases, left side in 70 cases). Reflex change was present in 32 cases (19.6\%). Sphincter involvement and sexual dysfunction were detected in $8(4.9 \%)$ and $2(1.2 \%)$ patients, respectively. The operated intervertebral lumbar disc spaces are summarized in Table 1.

Table 1: Operated intervertebral lumbar disc spaces in the studied population

\begin{tabular}{|l|l|}
\hline Levels & Frequency (\%) \\
\hline L4-L5, L5-S1 & $63(38.7)$ \\
\hline L4-L5 & $44(27)$ \\
\hline
\end{tabular}




\begin{tabular}{|c|c|}
\hline L5-S1 & $23(14.1)$ \\
\hline L3-L4, L4-L5 & $7(4.3)$ \\
\hline L2-L3 & $2(1.2)$ \\
\hline $\begin{array}{l}\text { L3-L4, L4-L5, L5- } \\
\text { S1 }\end{array}$ & $4(2.5)$ \\
\hline L3-L4 & $7(4.3)$ \\
\hline L2-L3, L4-L5 & $12(7.4)$ \\
\hline L1-L2 & $1(0.6)$ \\
\hline
\end{tabular}

Among the studied patients, laminectomy plus discectomy was performed in 42 cases (25.8\%), hemi-laminectomy plus discectomy was performed in 117 cases (71.8\%), and laminectomy plus discectomy with fusion was performed in 4 cases (2.4\%). The mean hospital stay was $4.03 \pm 1.35$ (range: $2-11$ ) days after operation. Complications were present in 8 cases (4.9\%). Study findings in two genders are summarized and compared in Table 2.

Table 2: Study findings in female and male patients with operated lumbar disc herniation

\begin{tabular}{|c|c|c|c|}
\hline Variables & $\begin{array}{c}\text { Female } \\
(\mathrm{n}=86)\end{array}$ & $\begin{array}{c}\text { Male } \\
(\mathrm{n}=77)\end{array}$ & p-value \\
\hline Sensory deficit & $57(66.3)$ & $51(66.2)$ & 0.99 \\
\hline Motor deficit & $52(60.5)$ & $32(41.6)$ & $0.01^{*}$ \\
\hline $\begin{array}{c}\text { Positive Lasegue } \\
\text { test }\end{array}$ & $60(69.8)$ & $66(85.7)$ & $0.01^{*}$ \\
\hline Reflex change & $17(19.8)$ & $15(19.5)$ & 0.96 \\
\hline $\begin{array}{c}\text { Sphincter } \\
\text { involvement }\end{array}$ & $4(4.7)$ & $4(5.2)$ & 0.87 \\
\hline \begin{tabular}{c} 
Sexual dysfunction \\
\hline
\end{tabular} & $0(0)$ & $2(2.6)$ & 0.13 \\
\hline
\end{tabular}

are summarized and compared in Table 3.

Accordingly, motor deficit was significantly higher in females $(P=0.01)$ and positive Lasegue test was more frequent in males $(P=0.01)$. Other findings were comparable between two Accordingly, Lasegue test was positive significantly lower in patients over 60 years. Other findings were comparable between age groups. genders. Study findings in different age groups

Table 4: Study findings in different age groups of patients with operated lumbar disc herniation

\begin{tabular}{|c|c|c|c|c|c|}
\hline Variables & $\begin{array}{r}\leq 40 \quad y r s \\
(n=64)\end{array}$ & $\begin{array}{l}40-50 \text { yrs } \\
(n=46)\end{array}$ & $\begin{array}{l}51-60 \text { yrs } \\
(n=33)\end{array}$ & $\begin{array}{rr}>60 & \text { yrs } \\
(n=20) & \end{array}$ & $\begin{array}{c}p- \\
\text { value }\end{array}$ \\
\hline $\begin{array}{l}\text { Sensory } \\
\text { deficit }\end{array}$ & 48(71.9) & $30(65.2)$ & $19(57.6)$ & 13(65) & $6^{0.5}$ \\
\hline $\begin{array}{l}\text { Motor } \\
\text { deficit }\end{array}$ & $32(50)$ & $23(50)$ & $15(45.5)$ & $14(70)$ & $4^{0.3}$ \\
\hline $\begin{array}{c}\text { Positive } \\
\text { Lasegue test }\end{array}$ & $49(76.6)$ & $40(87)$ & $26(78.8)$ & $11(55)$ & $4^{* 0.0}$ \\
\hline $\begin{array}{l}\text { Reflex } \\
\text { change }\end{array}$ & $17(26.6)$ & $7(15.2)$ & $5(15.2)$ & $3(15)$ & $6^{0.3}$ \\
\hline Sphincter & $5(7.8)$ & $1(2.2)$ & $0(0)$ & $10(2)$ & 0.1 \\
\hline
\end{tabular}




\begin{tabular}{|c|c|c|c|c|c|}
\hline involvement & & & & 9 \\
\hline $\begin{array}{c}\text { Sexual } \\
\text { dysfunction }\end{array}$ & $2(3.1)$ & $0(0)$ & $0(0)$ & $0(0)$ & \multicolumn{2}{|l|}{0.3} \\
\hline
\end{tabular}

Data are presented as frequency(\%); ${ }^{*} p$-value $<0.05$ is significant.

\section{Discussion}

In the present study, profiles of 163 patients with operated lumbar disc herniation were reviewed. They were 86 females (52.8\%) and 77 males (47.2\%). In a similar study by Mehrazin et al. (7) there were 56 males and 45 females. Pietilä et al. (9) studied 165 operated patients with lumbar disc herniation, including 105 males and 60 females. In contrast to these two studies, the rate of females was higher in the present investigation, possibly due to this fact that females do relatively heavier daily tasks in this region of the country comparing with females in other areas. The mean age of our patients was $44.85 \pm 0.91$ (range: $22-78$ ) years, similar to the reported mean age of the patients in the study by Mehrazin et al. (7), which was 40.43 years. The peak age of lumbar disc herniation has been reported between 30 and 50 years $(1,2)$. Our results were also in this range. Similar to the findings of Mirhoseini (6), the mean duration of hospital stay in our patients was 4.03 days. The main symptom of the patients in the present work before surgery was low back pain (97.9\%). Radicular pain was present in $96.9 \%$ of the studied population. All the patients operated in the study by Mehrazin et al. (7) had low back pain before operation. It should be noted that occurrence of disc herniation ameliorates previous back pain and is usually along with radicular pain. Radicular pain was reported in $90 \%$ of the patients investigated by Mehrazin et al. (7), and in 99\% of the patients in another study by Mirhoseini (6). The rate of sensory deficient in our patients (66.3\%) was similar to that of the study by
Mehrazin et al. (7), however, it cannot be compared with the reported rate by Mirhoseini (6) as he reported sensory deficits and reflex abnormalities together. Similarly, in a study by Porchet et al. (8) on operated herniated discs with extreme lateral disc herniation, sensory deficits were reported in $46.6 \%$ of the cases. The Lasegue test was present in $77.3 \%$ of our patients, similar to the reported rate $(72.3 \%)$ by Mehrazin et al (7). In the current study, reflex abnormalities were present in $19.6 \%$ of the cases. The sphincter and sexual abnormalities were present in $4.9 \%$ and $1.2 \%$, respectively. Motor deficit was present in $51.5 \%$ of our patients. This rate was $27 \%$ in the study by Mirhoseini (6), $78.8 \%$ in the study by Porchet et al (8), and $82.4 \%$ in the study by Mehrazin et al. (7). The lower rate of motor deficit in our study comparded to other reports may indicate an early attendance of these patients seeking advice and treatment in our center.

In conclusion, this study for the first time in this region of Iran showed that cases with operated lumbar disc herniation are similar to patients in other studies in terms of preoperational sign and symptoms.

\section{Conflicts of interest}

The authors declare that they have no conflict of interest. 


\section{References}

1. American Surgeon's Editorial. Herniated Disc-Fact sheet. Am Neurolog Surg 2004; 4:1-12.

2. Roberts S, Evans H, Trivedi J, Menage J. Histology and pathology of the human intervertebral disc. J Bone Joint Surg Am 2006;88(2):10-14.

3. De Beeck, Rik Op, and Hermans Veerle. Research on Work-Related Low Back Disorders, 3rd Ed. Institute for Occupational Safety and Health/European Agency for Safety and Health at Work, Brussels, 2000.

4. Pouriesa M, Fouladi RF, Mesbahi S. Disproportion of end plates and the lumbar intervertebral disc herniation. Spine J. 2013;13(4):402-7.

5. Olmarker K, Blomquist J, Strömberg J, Nannmark U, Thomsen P, Rydevik B. Inflammatogenic properties of nucleus pulposus. Spine (Phila Pa 1976) 1995;20(6):665-669.

6. Mirhoseini SA. Evaluation of 754 surgically treated lumbar disc herniation. JRMS 2003; 8(3):15-18.

7. Mehrazin M, Vafaei SH. Surgical results in lumbar disc (analysis of 101 cases). Teb Va tazkieh 2003; 48:32-38.

8. Porchet F, Fankhauser H, de Tribolet N. Extreme lateral lumbar disc herniation: clinical presentation in 178 patients. Acta Neurochir (Wien) 1994;127(3-4):203-209.

9. Pietilä TA, Stendel R, Kombos T, Ramsbacher J, Schulte T, Brock M. Lumbar disc herniation in patients up to 25 years of age. Neurol Med Chir (Tokyo) 2001;41(7):340-344.

10. Janardhana AP, Rajagopal, Rao S, Kamath A. Correlation between clinical features and magnetic resonance imaging findings in lumbar disc prolapse. Indian J Orthop 2010;44(3):263-269.

11. Jain S, Kumar S. Correlation between clinical features and magnetic resonance imaging findings in lumbar disc prolapse. Indian J Orthop 2011;45(2):105. 